\title{
A clinical practice for the hippocampal neurogenesis by chronobiological therapy
}

\author{
Masaki Shiozawa ${ }^{1}$ and Kenjiro Watanabe ${ }^{1}$ \\ ${ }^{1}$ National Hospital Organization Kikuchi Hospital
}

June 1, 2021

\begin{abstract}
Background: In 1965 Altman achieved the hippocampal neurogenesis in rats. In addition, when enough activities are provided in the daytime, and it is suggested that the consolidation of the memory during sleep will be achieved by hippocampal neurogenesis. Aims: We show a recovery method about dementia of neurodegenerative diseases on this article. We introduce our clinical practice of the chronobiological therapy regarding 6 dementia cases. Method: We provided the chronobiological therapy based on awakening-sleep rhythm by daily medical care. We examined autonomic nervous disorders and fluctuating cognition using physical examination. We performed the medication to promote the changes from sleep to awakening-activities in morning. In daytime, our occupational therapy was set, and awakening-activities was made stable. At night we gave the medication to make an active state decreased and stabilize deep sleep. The clinical evaluation was carried out by psychological examination. And Voxel-based Specific Regional Analysis System for Alzheimer's Disease (VSRAD) of Magnetic Resonance Imaging (MRI), which had been already established, was performed. The conventional study in VSRAD showed the state that the brain atrophy was progressive. Results: About Z-score showing the hippocampal atrophy in VSRAD we accomplished the improvement of 1.28 points from 0.03 about six dementia cases by the chronobiological therapy. These improvements were accompanied by the better changes of the cognitive functions. Conclusion: We speculate that the hippocampal neurogenesis may be derived by reconstructing awakening-sleep rhythm using the chronobiological medicines. If neurogenesis is more dominant than neurodegeneration, dementia associated with the neurodegeneration can be treated.
\end{abstract}

\section{ABSTRACT}

Background: In 1965 Altman achieved the hippocampal neurogenesis in rats. In addition, when enough activities are provided in the daytime, and it is suggested that the consolidation of the memory during sleep will be achieved by hippocampal neurogenesis.

Aims: We show a recovery method about dementia of neurodegenerative diseases on this article. We introduce our clinical practice of the chronobiological therapy regarding 6 dementia cases.

Method: We provided the chronobiological therapy based on awakening-sleep rhythm by daily medical care. We examined autonomic nervous disorders and fluctuating cognition using physical examination. We performed the medication to promote the changes from sleep to awakening-activities in morning. In daytime, our occupational therapy was set, and awakening-activities was made stable. At night we gave the medication to make an active state decreased and stabilize deep sleep. The clinical evaluation was carried out by psychological examination. And Voxel-based Specific Regional Analysis System for Alzheimer's Disease (VSRAD) of Magnetic Resonance Imaging (MRI), which had been already established, was performed. The conventional study in VSRAD showed the state that the brain atrophy was progressive.

Results: About Z-score showing the hippocampal atrophy in VSRAD we accomplished the improvement of 1.28 points from 0.03 about six dementia cases by the chronobiological therapy. These improvements were accompanied by the better changes of the cognitive functions. 
Conclusion: We speculate that the hippocampal neurogenesis may be derived by reconstructing awakeningsleep rhythm using the chronobiological medicines. If neurogenesis is more dominant than neurodegeneration, dementia associated with the neurodegeneration can be treated.

\section{What's known}

The progressive brain atrophy of neurodegenerative diseases has been shown neuropathologically.

The conventional study in VSRAD showed the state that the brain atrophy was progressive.

\section{What's new}

We showed the chronobiological therapy to produce the improvement of hippocampal atrophy clinically in VSRAD study.

It is suggested that this improvement is based on hippocampal neurogenesis.

\section{INTRODUCTION}

It is reported that accumulation of amyloid $\beta$ may cause fragmentation of sleep. ${ }^{1}$ The accumulation of amyloid $\beta$ may be controlled by metabolism of lactate through the astrocytes in conjunction with sleep-wake cycle. The suprachiasmatic nuclei and pineal gland control melatonin levels, which are elevated in darkness and decrease promptly in light and build sleep-wake cycle. ${ }^{2,3}$ When sleep is provided by melatonin, default mode network is seen in non-REM (rapid eye movement) sleep. The information of what is experienced in the daytime are moved in the brain during non-REM sleep through default mode network. ${ }^{4,5}$ Furthermore, memory consolidation occurs during non-REM sleep and it may be performed by neurogenesis of the hippocampal dentate gyrus. ${ }^{6,7}$

The recent studies are successful in the hippocampal neurogenesis in vivo but have not continued to clinical application. ${ }^{8,9}$ The neurogenesis by herbal medicine, which constitute the traditional Chinese medicine or Japanese Kampo Medicine, has been reported. ${ }^{10,11}$ It is expected that there is the element which connects neurogenesis with clinical application in those medicine. Neuronal loss under neurodegeneration or aging is always occurring in the brain of all adults potentially. ${ }^{12}$ The hippocampal neurogenesis which occurred in the adult human brain was confirmed in the precedent study. ${ }^{13}$ If clock genes work in the body, circadian rhythm will be stable, and neurogenesis would occur in the brain. ${ }^{14,15}$

Circadian rhythm is seen in a creature influenced by light/dark rhythm on the earth. It forms awakening-sleep rhythm, and the disorder of awakening-sleep rhythm produces each autonomic nervous disorder. ${ }^{16,17,18,19}$ In the brain, during daytime there is fluctuating cognition that awakening (action) is mixed by rest (sleep). ${ }^{20}$ During night there is the abnormality of rapid eye movement (REM) sleep (many dreams) that awakening is strengthened. If patients have autonomic nervous disorder, in the circulatory organ, the increase of blood pressure or heart rates will be insufficient, and this condition will produce orthostatic hypotension or bradycardia during awakening by day. On the other hand, high blood pressure will be observed during sleep at night, although the blood pressure during sleep will be low normally. ${ }^{21,22}$ In the digestive organs, sthenia of appetite and peristalsis will be observed by night and loss of appetite will be seen in morning. ${ }^{23}$ In the bladder, pollakiuria will be recognized without the storage of urine during night. ${ }^{24}$ Or in the muscle stiffening or atonia in sleep will remain, although the muscle will adapt voluntary movements after awakening. ${ }^{25,26}$ If, against these dysfunctions, each organ awakes all together in the daytime, maintains an activity status and forms a sleep status in nighttime, the disorder of awakening-sleep rhythm will be improved. When awakening-sleep rhythm is fixed, the rise of melatonin level happens in 14 hours after awakening and sleep is induced. ${ }^{3}$ In addition, during stabilized sleep the default mode network connects perception and experience regarding active tasks, and the hippocampal neurogenesis performs the memory consolidation. ${ }^{5,6}$

\section{METHODS}

We treated the status of each dementia chronobiologically. We reconstructed the awakening-sleep rhythm about brain and other organs with internal medicines and Japanese Kampo Medicines (JKMs). We set 
rehabilitation at the same time and promoted the use of brain in daytime.

\subsection{CLINICAL EXAMINATIONS}

We carried out a chest X-ray examination and evaluated degree of the cardiac hypertrophy by cardiothoracic ratio (CTR). We evaluated the existence of pneumonia and pleural effusion at the same time. We performed Schellong's test to detect orthostatic hypotension. We carried out an electrocardiography (ECG), measured bradycardia and QT intervals, and evaluated bradycardic changes. And we also measured brain natriuretic peptide (BNP) to examine degree of the heart load. From these inspections mainly, we diagnosed the autonomic nervous disorder of the circulatory organ. A urinalysis and the interview about the urination pattern in daytime and night diagnosed the autonomic nervous disorder of the bladder. When we detected constipation and diarrhea, or hypoproteinemia though patients did not suffer from a kind of gastrointestinal disease and a meal intake was stable, we considered a gastrointestinal peristalsis disorder. By the electroencephalography (EEG), we detected the basic rhythm of the alpha wave and evaluated presence of mixture of slow waves such as $\vartheta$ train or $\delta$ waves and mixture of the sleep status such as $\beta$ spindle and diagnosed the fluctuating cognition (FC). When awakening (activity) mixed rest (sleep) during daytime, we interviewed the frequency and severity of rapid eye movement sleep behavior disorder (RBD) and frequency to be aware of a dream. As for the examination of psychology, Mini-Mental State Examination (MMSE) and the brief questionnaire form of the Neuropsychiatric Inventory (NPI-Q) were held. ${ }^{27,28}$ Patients were examined about neurologic symptoms such as parkinsonism, cerebellar ataxia and so on. Magnetic Resonance Imaging (MRI) was performed for head scan and diffuse or localized brain atrophies were detected together with cerebrovascular changes. And Voxel-based Specific Regional Analysis System for Alzheimer's Disease (VSRAD), which is the software used widely, was conducted. ${ }^{29}$ In the conventional study, as for the Z-scores indicating the degree of the hippocampal atrophy, it is shown that those values grow bigger with the brain atrophy in the progression of dementia. ${ }^{30} 1.0$ tesla MRI and version of VSRAD plus were used in VSRAD of MRI before September in 2017. 1.5 tesla MRI and version of VSRAD advance 2 were used after September in 2017.

\subsection{MEDICATIONS FOR AUTONOMIC NERVOOUS DISORDERS AND RECONSTRUC- TION OF AWAKENING-SLEEP RHYTHM}

When there were orthostatic hypotension, prolonged QT interval, or bradycardia with cardiomegaly or high brain natriuretic peptide, the autonomic nervous disorder of circulatory organ was considered. And we used a diuretic or Toki-Shakuyaku-San to reduce heart load. High blood pressure was treated mainly by angiotensin II receptor blocker (ARB) ${ }^{31}$ When pollakiuria was detected without the storage of urine during night, we used Hachimi-Jio-Gan. The diuretics in morning also contributed to construction of the urination rhythm. In the case with arthralgia at the same time, we used Gosha-Jin-Ki-Gan. When the need of improvement of gastrointestinal peristalsis was considered, we treated lansoprazole in morning and tried to make the circadian rhythm. Lansoprazole stabilizes the receptive relaxation of stomach in morning. ${ }^{32}$ When we diagnosed loss of appetite, low motivation, and muscle weakness of legs, so-called frail syndrome, we used NinjinYoei-To. When electroencephalogram (EEG) pointed out fluctuating cognition, or the interview confirmed the change of the cognitive function in the day or week, we chose Japanese Kampo Medicines (JKMs), which contained Toki, Japanese Angelica Root, including ligustilide, for the stabilization of awakening to reconstruct awakening-sleep rhythm. When it was necessary to make the end of activity towards night, we chose Japanese Kampo Medicines (JKMs) containing Chotoko, Uncaria Hook, including rhynchophylline. In other words, the Yokkan-San is a representative reconstructing the awakening-sleep rhythm. With the combination of clonazepam, we made experiences of the dream fewer and we performed a stabilization of the sleep by nitrazepam. ${ }^{33,34}$

\subsection{REHABILITATIONS FOR RECONSTRUCTION OF AWAKENING-SLEEP RHYTHM AND MEMORY CONSOLIDATION}

The light of the hospital room is turned on at 6:00 a.m. and the inpatients receive photic stimulation every morning. ${ }^{35}$ When the awakening-sleep rhythm was reconstructed, the patients became able to participate in occupational therapy constantly. The rehabilitation was scheduled in a regular week plan. The patients 
with severe dementia met into Murofushi care system in the dementia disease treatment ward. They sat at table of "family members" and participated in the group occupational therapy in a regular week plan. ${ }^{36}$ Because the patients having defects of memory in dementia are in the experience of the loss about memory and unable to use perspective memory, they tend to be seized with anxiety. The experience of the loss about memory will induce anxiety or depression. The memory about the near past is the origin of time axes for predictions and the prediction from the origin is perspective memory, which is the expectation of the near future. The patients with short-term memory impairment lost the origin, cannot know what is planned or will happen, and show continuing anxiety. We changed the continuation of moments of uneasiness into the mental status in which comfortable senses were continued. By the condition that the patients with severe dementia sat around the round table, they saw their faces each other, could exchange greetings and smiles, and spoke to each other. They did not become alone and continued to get the stimulation of smile. And they changed into the existence letting the other patients feel relieved and formed "family members". They were freed from uneasiness, felt calm and after that participated in group occupational therapy in daytime.

\section{RESULTS}

The study included six patients who were followed in National Hospital Organization Kikuchi Hospital between July 2012 and December 2019. The three patients provided informed consent for the publication of their medical history, laboratory, imaging, treatment, and follow-up data. They were informed that data that were collected in medical records would be used for research study in accordance with privacy rule.

[Case 1] An 86-year-old man presented with a four-year history of memory disturbance. Cholinesterase inhibitor was prescribed to treat dementia caused by Alzheimer's disease. The medication of donepezil, which was one of anti-Alzheimer's disease medicines, started at the age of 82 years and $5 \mathrm{mg}$ of donepezil was kept. He scored 23/30 on the Mini Mental State Examination (MMSE) at the age of 83 years, other findings were considered, and was diagnosed as Alzheimer's disease. ${ }^{37,38}$ His chest X-ray did not show cardiomegaly. He did not show autonomic nervous disorders of orthostatic hypotension. His cardiothoracic ratio was $42.62 \%$, QT interval on electrocardiogram was $418 \mathrm{~ms}$, and brain natriuretic peptide was $41.37 \mathrm{pg} / \mathrm{mL}$. His Z-score of the medial temporal lobe in VSRAD, which was performed by 1.0 tesla Magnetic Resonance Imaging (MRI) and version of VSRAD plus, was 1.53 .

Chronobiological medication was provided to stabilize awakening-sleep rhythm. $0.25 \mathrm{mg}$ of clonazepam at night was added for daytime somnolence and $15 \mathrm{mg}$ of lansoprazole was used for gastric region discomfort. At the age of 85 years, he was admitted to our hospital with disinhibition of anger and face flush. His cardiothoracic ratio was $43.26 \%$ and QT interval was 386ms. We used $7.5 \mathrm{~g}$ of Oren-Gedoku-To, which reduced main psychiatric symptoms, and $7.5 \mathrm{~g}$ of Choto-San, which made a closure of action. We continued $15 \mathrm{mg}$ of lansoprazole to make gastrointestinal movement from morning. We gave $2.5 \mathrm{mg}$ of nitrazepam to stabilize his sleep status. After donepezil cancellation, Oren-Gedoku-To was changed to $6 \mathrm{~g}$ of Ninjin-Yoei-To, which promoted an activity and the use of memory during daytime.

His awakening-sleep rhythm became stable. The patients with dementia met into Murofushi care system in the dementia disease treatment ward and he sat at table of "family members." To stabilize awakening and activity of the daytime, he participated in the group occupational therapy.

Two months after, MMSE score became 19/30 from 14/30 and Z-score of the medial temporal lobe in VSRAD became 4.14 from 4.17 , which were examined by 1.5 tesla MRI and version of VSRAD advance 2 .

[Case 2] A 72-year-old man presented with a three-year history of memory disturbance. He suffered low motivation after his wife's death at the age of 67 years. At the age of 69 years, he showed memory deterioration and his Z-score of the medial temporal lobe, which was performed by 1.0 tesla Magnetic Resonance Imaging (MRI) and version of VSRAD plus, was 1.49. He scored 26/30 on MMSE. At the age of 70 years, his Z-score by the same VSRAD was 1.67. He was diagnosed as Alzheimer's disease, and cholinesterase inhibitor, donepezil, was given. However, he scored 25/30 on MMSE and wandered all night. He was admitted to our hospital and donepezil was reduced from 5 to $3 \mathrm{mg}$. The family doctor prescribed 50mg of sitagliptin phosphate hydrate against type II diabetes and we continued to use it. His chest X-ray did not 
reveal cardiomegaly. He did not show the autonomic nervous disorders of circulatory organ, such as his cardiothoracic ratio was $49.2 \%$, QT interval on electrocardiogram was $413 \mathrm{~ms}$, and brain natriuretic peptide was $63.17 \mathrm{pg} / \mathrm{mL}$. His systolic blood pressures were 150 to $182 \mathrm{mmHg}$. $5 \mathrm{mg}$ of amlodipine besilate and $40 \mathrm{mg}$ of valsartan was given for high blood pressure.

We started chronobiological medication, such as $5 \mathrm{~g}$ of Yokkan-San for construction of awakening-sleep rhythm and $1.25 \mathrm{~g}$ of Toki-Shakuyaku-San for reduction of cardiac load. $0.25 \mathrm{mg}$ of clonazepam was used for REM (rapid eye movement) sleep behavior disorder and $2.5 \mathrm{mg}$ of nitrazepam was prescribed to stabilize his sleep status. He scored 19/30 on MMSE. MRI revealed that Z-score of the medial temporal lobe was 2.05, which was performed by 1.5 tesla MRI and version of VSRAD advance 2 .

His awakening-sleep rhythm were stable soon and in daytime he participated in the occupational therapy in the inpatient's ward to strengthen awakening, activity movement. And he left our hospital two months after. His chronobiological medication and reinforcement of the awakening-sleep rhythm were maintained. He stayed the nursing home with day service rehabilitation for six months and after that he lived in his house with his family, continuing day service.

At the age of 72 , in about one year and two months, his MMSE score was 23/30. And Z-score by 1.5 tesla Magnetic Resonance Imaging (MRI) and version of VSRAD advance 2 was 1.92 . His brain natriuretic peptide was $14.3 \mathrm{pg} / \mathrm{mL}$.

[Case 3] A 65-year-old woman presented with a three-year history of memory disturbance. She suffered bipolar disorder since she was 58 years old. The doctor in charge prescribed $4 \mathrm{mg}$ of risperidone and $400 \mathrm{mg}$ of sodium valproate to stabilize her mood. At the age of 62 years, she was not able to do money management, because of her memory decline. At the age of 63 years, she often complained that she was spoken ill and was admitted to our hospital. She did not show her chest X-ray findings. As her cardiothoracic ratio was $51.26 \%$ and QT interval on electrocardiogram was $423 \mathrm{~ms}$, she did not show autonomic nervous disorders of circulatory organ. She scored $17 / 30$ on MMSE and showed that Z-score of the medial temporal lobe was 1.48, which was performed by 1.0 tesla Magnetic Resonance Imaging (MRI) and version of VSRAD plus. At the age of 70 years, his Z-score by the same VSRAD was 1.67. She was diagnosed as Alzheimer's disease.

Her chronobiological medication were started. $7.5 \mathrm{~g}$ of Bohu-Tsusho-San, which was used for irritability and itchy status, was added to the mood stabilizers. This Japanese Kampo medicine also provides the stabilization of the awakening. $2.5 \mathrm{mg}$ of nitrazepam was used as a sleep-inducing drug. Two months after hospitalization, $0.25 \mathrm{mg}$ of clonazepam was added for the reduction of REM (rapid eye movement) sleep and the stabilization of awakening and sleep rhythm.

She participated in daily occupational therapy to strengthen awakening, activity movement. She left our hospital in nine months and attended the occupational therapy in outpatient unit. When she was not able to have breakfast because of her appetite loss, $15 \mathrm{mg}$ of lansoprazole in the morning was added to make the rhythm of receptive relaxation of stomach.

At the age of 64 , dizziness in daytime and many dreams in sleep were recognized. 2.5g of Yokkan-San-KaChinpi-Hange was added to stabilize awakening-sleep rhythm. She scored 19/30 on MMSE and showed that the Z-score, which was examined by 1.5 tesla MRI and version of VSRAD advance 2, was 0.93 at the age of 65.

[Case 4] A 93-year-old woman presented with a 7-year history of fluctuating cognition and memory disturbance. She often talked to towards the photographs and wall. She became to have visual hallucination of a person at the age of 87 years. The medication of $3 \mathrm{mg}$ of donepezil was started at the age of 93 . However, she was seized with a delusion state, taken to the psychiatry, and diagnosed as dementia with Lewy bodies ${ }^{39,40}$ She scored 10/30 on MMSE at the age of 93 years. Antipsychotics, such as $25 \mathrm{mg}$ of quetiapine fumarate or 5mg of olanzapine, were given, but her hallucination and delusion status rather turned worse. She was introduced to our hospital for admission. Her chest X-ray showed $51.35 \%$ of cardiothoracic ratio. QT interval on electrocardiogram was $447 \mathrm{~ms}$ and brain natriuretic peptide was $275.4 \mathrm{pg} / \mathrm{mL}$. Her autonomic 
nervous system disorders were the QT interval prolongation and chronic heart failure.

We started chronobiological medication and canceled donepezil. $0.25 \mathrm{mg}$ of clonazepam in the night were used for the reduction of REM (rapid eye movement sleep) behavior disorder. $2.5 \mathrm{mg}$ of amlodipine besilate, $80 \mathrm{mg}$ of valsartan, and $20 \mathrm{mg}$ of furosemide were given for high blood pressure. Valsaltan was one of angiotensin II receptor blockers, which was used against the instability of blood pressure caused by cardiac autonomic nervous disorders. Furosemide for urination in the morning was one of diuretics. 15 mg lansoprazole was used to make receptive relaxation of stomach in the morning. $75 \mathrm{mg}$ of tiapride, which was the small amount of antipsychotic, was prescribed against her hallucination and delusion. $5 \mathrm{~g}$ of Oren-Gedoku-To was added to get rid of irritation and to make falling sleep. $5 \mathrm{~g}$ of Choto-San was provided to make the decreases of the awakening in the night.

The patients with dementia met into Murofushi care system in the dementia disease treatment ward. She sat at table of "family members" and participated in the group occupational therapy in the daytime. On the 52nd day after hospitalization, she suffered parkinsonism and motor apraxia. Both Japanese Kampo Medicines were changed to 7.5g of Yokkan-San-Ka-Chinpi-Hange and 2.5g of Hochu-Ekki-To, which stabilized awakening-sleep rhythm and reduced parkinsonism and promoted the motivation. Because of hypokalemia, furosemide was changed to $25 \mathrm{mg}$ of spironolactone, which was one of diuretics and promoted the action of bladder in the morning.

In two months, the severity of Neuropsychiatric Inventory-Questionnaire became 9/36 from 20/36 and her Z-score of the medial temporal lobe in 1.5 tesla Magnetic Resonance Imaging (MRI) and version of VSRAD advance 2 became 2.33 from 2.37

[Case 5] A 95-year-old woman presented with a 15-year history of memory disturbance. She showed delusion of being stolen from since she was 80 years old. 1.0 tesla MRI and version of VSRAD plus were performed at the age of 86. Her Z-score of the medial temporal lobe in VSRAD was 3.43 and She scored 27/30 on MMSE. $7.5 \mathrm{~g}$ Yokkan-San was prescribed against her irritability and fluctuating cognition. In the same year $3 \mathrm{mg}$ of donepezil, which was one of cholinesterase inhibitors, was started for her fluctuating cognition. However, her cognitive function deteriorated progressively. The irritability was reduced, and only $3 \mathrm{mg}$ of donepezil was continued at the age of 91 . She suffered syncope and vertigo at the age of 94 years. She was absentminded in the daytime and showed REM (rapid eye movement) sleep behavior disorder by night. She was admitted to our hospital for the treatment of BPSD (behavioral and psychological symptoms of dementia) and the peristaltic gastrointestinal tract disorder. Her chest X-ray showed $48.33 \%$ of cardiothoracic ratio. QT interval on electrocardiogram was $424 \mathrm{~ms}$ and brain natriuretic peptide was $26.76 \mathrm{pg} / \mathrm{mL}$. However, the instability of systolic blood pressure was shown in the range of 76 to $155 \mathrm{mmHg}$. Her cardiac autonomic nervous disorder was considered. She was diagnosed as dementia with Lewy bodies.

Chronobiological medication was provided to stabilize awakening sleep rhythm. 0.125mg of clonazepam at night was added to stabilize the sleep status and $15 \mathrm{mg}$ lansoprazole was given to make the receptive relaxation of stomach in the morning. She took $5 \mathrm{mg}$ of mosapride citrate hydrate three times a day against dysperistalsis. 2.5g of Yokkan-San-Ka-Chinpi-Hange was started for construction of awakening-sleep rhythm and intestinal peristalsis. One week later, $660 \mathrm{mg}$ of magnesium oxide was added for constipation. However, the loss of appetite continued. She scored 14/30 on MMSE on the 30th day after the hospitalization. The gradual decrease of donepezil was started on the 49th day, and donepezil was canceled on the 77 th days. We started $5 \mathrm{~g}$ of Keishi-Ka-Shakuyaku-To, which promoted motion of intestine. She recovered her appetite and entered "family members" in the unit and participated in the group occupational therapy to stabilize awakening and activity of the daytime.

The severity of Neuropsychiatric Inventory-Questionnaire changed from 21/36 of the first day to $2 / 36$ about 170 days after the hospitalization. And her Z-score of the medial temporal lobe in 1.5 tesla Magnetic Resonance Imaging (MRI) and version of VSRAD advance 2 became 5.58 from 5.7.

[Case 6] A 73-year-old woman presented with a five-year history of fluctuating cognition (FC). She showed insomnia at the age of 63 , but did not take the medicine. She visited our hospital for amnesia at the age of 
68. Her basic activity of $11 \mathrm{~Hz}$ alpha waves were mixed by theta train on EEG, that is, fluctuating cognition was detected. Her chest X-ray showed $47.71 \%$ of cardiothoracic ratio. QT interval on electrocardiogram was $424 \mathrm{~ms}$ and brain natriuretic peptide was $39.29 \mathrm{pg} / \mathrm{mL}$. Her blood pressure was high, such as the systolic blood pressure was $168 \mathrm{mmHg}$ and diastolic pressure was $110 \mathrm{mmHg}$. Her Z-score, which was performed by 1.0 tesla Magnetic Resonance Imaging (MRI) and version of VSRAD plus, was 1.50. Her falling asleep was bad and there was somniloquy in the night. She was hard to get up and had no appetite in the morning, and her body came to be active after lunch. Her total score of MMSE was 22/30 and the recall was 1/3. She was diagnosed as dementia with Lewy bodies.

Chronobiological medication was started to reconstruct awakening-sleep rhythm. $15 \mathrm{mg}$ of lansoprazole in the morning was used for gastric region discomfort and appetite loss. $2.5 \mathrm{mg}$ of amlodipine besilate were given for high blood pressure. 10mg of furosemide for urination in the morning was one of diuretics. $0.5 \mathrm{mg}$ of clonazepam was used for REM (rapid eye movement) sleep behavior disorder and $2.5 \mathrm{mg}$ of nitrazepam was prescribed to stabilize his sleep status. $50 \mathrm{mg}$ of tiapride hydrochloride and 10mg of mianserin hydrochloride were prescribed for the stabilization of mood and the reduction of depressive state. In addition, we started $4.5 \mathrm{mg}$ of rivastigmine patch to treat the dementia with Lewy bodies. She participated in our occupational therapy twice a week in outpatient section. Because the activity in the daytime was provided when she participated in our occupational therapy, her awakening sleep rhythm was improved. On other days of a week, her awakening-sleep rhythm remained unstable. By the inspection after one year and five months, although her MMSE score was improved to $25 / 30$ and the recall was 2/3, Z-score, which was performed by 1.0 tesla Magnetic Resonance Imaging (MRI) and version of VSRAD plus, turned worse to 2.31, and QT interval in the electrocardiography extended to $434 \mathrm{~ms}$.

When she was 73 years old, her husband suffered from his cognitive deterioration and he showed violence to her. She began to fail the management of drugs and her fluctuating cognition became worse again. Then, she was admitted into our hospital to resume the reconstruction of the awakening-sleep rhythm. 1.5 tesla Magnetic Resonance Imaging (MRI) revealed her medial temporal lobar atrophy and her Z-score of medial temporal lobe in version of VSRAD advance 2 was 2.74. Her total score of MMSE was 25/30 and the recall was $2 / 3$. We gave her $7.5 \mathrm{~g}$ of Yokkan-San to reconstruct her awakening sleep rhythm. We prompted her to participate in occupational therapy to improve her activity of the daytime. Her MMSE score was 29/30 and the recall was $3 / 3$ on the 34 th day after hospitalization. The Z-score was 1.46 on the 82 th day.

\section{DATA ANALYSES}

Voxel-based Specific Regional Analysis System for Alzheimer's Disease (VSRAD) calculates the Z score that is a value indicating the atrophic degree of the medial temporal lobe. The $\mathrm{Z}$ scores at the time of the intervention with the chronobiological therapy were 1.48 to 5.7 and the average was 3.085 . The $\mathrm{Z}$ scores after the intervention were 0.93 to 5.58 and the average was 2.727 (Figure 1). The atrophic degrees of the medial temporal lobe were improved. The MMSE scores at the time of the intervention with the chronobiological therapy were 11 to 25 and the average was 16.2. The MMSE scores after the intervention were 10 to 29 and the average was 18.5 (Figure 2). Regarding Case 4 and 5, the severities of Neuropsychiatric InventoryQuestionnaire (NPI-Q) at the time of the intervention with the chronobiological therapy were 20 and 21, and the average was 20.5. The severities of NPI-Q after the intervention were 9 and 2, the average was 5.5 (Figure 3). These cases' BPSD (Behavioral and Psychological Symptoms of Dementia) was improved.

The VSRAD Z-scores at the time of the intervention with the chronobiological therapy were from 1.48 to 5.7, and the MMSE scores were from 11 to 25 points. This Pearson correlation coefficient was -0.353 , and they showed weak negative correlation (Figure 4). The Z-scores after the intervention were from 0.93 to 5.58 , and the MMSE scores were from 10 to 29 points. This Pearson correlation coefficient was -0.549 , and they showed negative correlation (Figure 5).

The $\mathrm{Z}$ scores at the time of the intervention with chronobiological therapy were 1.48 to 5.7 , and the $\mathrm{Z}$ scores after the intervention were 0.93 to 5.58. As for the Z-scores at the time of and after the intervention, the Pearson correlation coefficient was 0.965 , they showed strong positive correlation, and the irrelevant value 
was not seen (Figure 6). The MMSE scores at the time of the intervention with chronobiological therapy were 11 to 25, and the MMSE score after the intervention were 10 to 29. As for MMSE scores at the time of and after the intervention, the Pearson correlation coefficient of was 0.843 , they showed strong positive correlation, and the irrelevant value was not seen. (Figure 7)

We achieved the recovered 0.03 to 1.28 points of VSRAD Z-score. The Pearson correlation coefficient between these recovered points and the MMSE scores at the time of the intervention was 0.872 , and they demonstrated strong positive correlation (Figure 8). The Pearson correlation coefficient between these recovered points and the MMSE scores after the intervention was 0.740, and they demonstrated strong positive correlation (Figure 9).

In the chronobiological therapy, $15 \mathrm{mg}$ of lansoprazole and diuretics was chosen as the drug to promote awakening and activity in the morning. 20mg of furosemide or $25 \mathrm{mg}$ of spironolactone was prescribed for urination in the morning in Case 4. $4.5 \mathrm{mg}$ of rivastigmine was prescribed to make an awakening and activity in Case 6. 80mg of valsartan, which was one of angiotensin II receptor blockers (ARBs), was mainly used for adjustment of the blood pressure. 0.125 to $0.5 \mathrm{mg}$ of Clonazepam and $2.5 \mathrm{mg}$ of nitrazepam were selected to close an awakening and activity and stabilize sleep without REM (rapid eye movement sleep) behavior disorder (Table 1).

Japanese Kampo medicines (JKMs) were prescribed for start and closure of activities, and reconstructed awakening-sleep rhythm. 6g of Ninjin-Yoei-To, 1.25g of Toki-Syakuyaku-San, 2.5g of Hochu-Ekki-To, 7.5g of Bohu-Tsusho-San, 5 to 7.5g of Yokkan-San, 2.5 to 7.5g of Yokkan-San-Ka-Chinpi-Hange, 5g of KeishiKa-Shakuyaku-To, 5 to 7.5g of Oren-Gedoku-To, and 5 to 7,5g of Choto-San were used.In all cases, we used Japanese Kampo medicines including Toki, Japanese Angelica Root, and Chotoko, Uncaria Hook. 1 to 4g of Japanese Angelica Root was used, and 1 to $3 \mathrm{~g}$ of Uncaria Hook was used (Table 2 and 3).

\section{DISCUSSION}

The neurodegenerative disease with dementia such as Alzheimer's dementia has been regarded as a disease indicating progressive progress conventionally. ${ }^{41}$ We introduced the chronobiological therapy against dementia cases. We reduced fluctuating cognition and autonomic nervous dysfunction of each organ by reconstructing awakening and sleep rhythm. In addition, we made the patients participate in the rehabilitation for cognitive functions. We adjusted the balance of awakening and sleep rhythm, that is, a circadian rhythm, and arranged the schedule of activities.

Altman succeeded in hippocampal neuropoiesis in rats in $1965 .{ }^{42}$ The recent studies are successful in the hippocampal neurogenesis in vivo but have not continued to clinical application. ${ }^{13}$ The neurogenesis by herbal medicine, which constitute the traditional Chinese medicine or Japanese Kampo Medicine, has been reported. ${ }^{10,11}$ It is expected that there is the element which connects neurogenesis with clinical application in those medicine. ${ }^{43}$ Neuronal loss under neurodegeneration or aging is always occurring in the brain of all adults potentially. The hippocampal neurogenesis which occurred in the adult human brain was confirmed in the precedent study. ${ }^{12}$ We supposed that the neurogenesis was always occurring potentially. We thought that the hippocampal volume would be changed by the dominant factors based on the relation between the neurogenesis vs neurodegeneration, although many researchers are trying to develop the new one drug which would conduct neurogenesis.

When sleep is affected, amyloid $\beta$ level in the cerebrospinal fluid rises. ${ }^{44}$ On the other hand, the accumulation of amyloid $\beta$ may cause fragmentation of sleep. ${ }^{1}$ The accumulation of amyloid $\beta$ is a main cause of Alzheimer's disease. ${ }^{45}$ The melatonin controls circadian rhythm and the plasticity of the hippocampal nerves. ${ }^{46}$ NonREM sleep is constructed during sleep and, in the non-REM sleep, is in a condition that the information that was experienced at the daytime communicate through default mode network. ${ }^{4,5}$ Furthermore, natural sleep rhythm may regulate adult neurogenesis. Memory-consolidation may be achieved by neurogenesis of the hippocampal dentate gyrus during non-REM sleep. s. ${ }^{6,7,47}$ The exercise promotes neurogenesis together with the control of the daytime meal intake. ${ }^{48}$ 
There are Yin-Yang ups and downs, which is the way of thinking of both awakening-action and sleep-rest, in Japanese Kampo Medicine and we focused on awakening and sleep rhythm. ${ }^{49,50}$ Yin-Yang ups and downs, namely the traditional awakening and sleep rhythm, is the rhythm with the activity peak at about 11:00 a.m. and the sleep peak at about 11:00 p.m. In the recent studies the way of thinking of awakening and sleep rhythm becomes one of the chronobiology. In addition, it is expected that circadian clock genes become easy to act properly under the physical and psychological balance. ${ }^{51,52}$ If clock genes work in the body, circadian rhythm will be stable, and neurogenesis would occur in the brain. ${ }^{14,15}$ "Making the balance of person"

by Japanese Kampo Medicine is the adjustment of awakening and sleep rhythm and is the treatment of autonomic nervous dysfunction, and is the reconstruction of the circadian rhythm. Therefore, a potentiality to promote neurogenesis is expected in Japanese Kampo Medicine therapy. ${ }^{53,54}$

\section{REFERENCES}

1. Vanderheyden WM, Lim MM, Musiek ES, Gerstner JR. Alzheimer's Disease and Sleep-Wake Disturbances: Amyloid, Astrocytes, and Animal Models.J Neurosci. 2018; 38(12): 2901-2910. DOI: https://doi: 10.1523/JNEUROSCI.1135-17.2017

2. Brown GM. Light, melatonin and the sleep-wake cycle. J Psychiatry Neurosci. 1994; 19(5): 345-53.

3. Tordjman S, Chokron S, Delorme R, Charrier A, Bellissant E, Jaafari N, et al. Melatonin: Pharmacology, Functions and Therapeutic Benefits.Curr Neuropharmacol. 2017; 15(3): 434-443. DOI: https://doi: 10.2174/1570159X14666161228122115

4. Wilson RS, Mayhew SD, Rollings DT, Goldstone A, Hale JR, Bagshaw AP. Objective and subjective measures of prior sleep-wake behavior predict functional connectivity in the default mode network during NREM sleep.Brain Behav. 2019; 9(1): e01172. DOI: https://doi: 10.1002/brb3.1172. Epub 2018 Dec 4

5. Sormaz M, Murphy C, Wang HT, Hymers M, Karapanagiotidis T, Poerio G, et al. Default mode network can support the level of detail in experience during active task states. Proc Natl Acad Sci U S A.2018; 115(37): 9318-9323. DOI: https://doi: 10.1073/pnas.1721259115

6. Koyanagi I, Akers KG, Vergara P, Srinivasan S, Sakurai T, Sakaguchi M. Memory consolidation during sleep and adult hippocampal neurogenesis.Neural Regen Res. 2019; 14(1): 20-23. DOI: https://doi: 10.4103/1673-5374.243695

7. Navarro-Sanchis C, Brock O, Winsky-Sommerer R, Thuret S. Modulation of Adult Hippocampal Neurogenesis by Sleep: Impact on Mental Health.Front Neural Circuits. 2017; 11: 74. DOI: https://doi: 10.3389/fncir.2017.00074

8. Chen G, Rajkowska G, Du F, Seraji-Bozorgzad N, Manji HK. Enhancement of Hippocampal Neurogenesis by Lithium. J. Neurochem. 2000; 75, 1729-1734. DOI: https:// doi: 10.1046/j.14714159.2000.0751729.x

9. Sahay A, Scobie KN, Hill AS, O'Carroll CM, Kheirbek MA, Burghardt NS, et al. Increasing adult hippocampal neurogenesis is sufficient to improve pattern separation. Nature. 2011; 472(7344): 466-70. DOI: https://doi: 10.1038/nature09817

10. Wu L, Ran C, Liu S, Liao L, Chen Y, Guo H, et al. Jiaweisinisan facilitates neurogenesis in the hippocampus after stress damage.Neural Regen Res. 2013; 8(12): 1091-102. DOI: https://doi: 10.3969/j.issn.1673-5374.2013.12.004

11. Zheng G, Cheng W, Wang Y, Wang X, Zhao S, Zhou Y, et al. Ginseng total saponins enhance neurogenesis after focal cerebral ischemia. J Ethnopharmacol. 2011; 133(2): 724-728. DOI: https://doi: 10.1016/j.jep.2010.01.064

12. Nelson PT, Alafuzoff I, Bigio EH, Bouras C, Braak H, Cairns NJ, et al. Correlation of Alzheimer Disease Neuropathologic Changes With Cognitive Status: A Review of the Literature. J Neuropathol Exp Neurol. 2012; 71(5): 362-381. DOI: https://doi: 10.1097/NEN.0b013e31825018f7

13. Eriksson PS, Perfilieva E, Bjork-Eriksson T, Alborn AM, Nordborg C, Peterson DA, et al. Neurogenesis in the adult human hippocampus. Nat Med. 1998; 4(11): 1313-7. DOI: https://doi: 10.1038/3305

14. Borgs L, Beukelaers P, Vandenbosch R, Nguyen L, Moonen G, Maquet P, et al. Period 2 regulates neural stem/progenitor cell proliferation in the adult hippocampus. BMC Neurosci. 2009; 10: 30. 
DOI: https://doi: 10.1186/1471-2202-10-30

15. Tamai S, Sanada K, Fukada Y. Time-of-Day-Dependent Enhancement of Adult Neurogenesis in the Hippocampus. PLoS One. 2008; 3(12): e3835. DOI: https://doi: 10.1371/journal.pone.0003835

16. Waterhouse J, Fukuda Y, Morita T. Daily rhythms of the sleep-wake cycle. J Physiol Anthropol. 2012; 31(1): 5. DOI: https://doi: 10.1186/1880-6805-31-5

17. Opperhuizen A, Foppen E, Jonker M, Wackers P, Faassen M, Weeghel M, et al. Effects of Light-atNight on the Rat Liver. A Role for the Autonomic Nervous System. Front Neurosci. 2019; 13: 647. DOI: https:// doi: 10.3389/fnins.2019.00647

18. Almoosawi S, Vingeliene S, Gachon F, Voortman T, Palla L, Johnston JD, et al. Adv Nutr. 2019; 10(1): 30-42. DOI: https://doi: 10.1093/advances/nmy070

19. Makimoto H, Shimizu K, Fujiu K, Lin T, Oshima T, Amiya E, et al.Int Heart J. 2018; 59(6): 1352-1358. DOI: https://doi: 10.1536/ihj.17-561

20. Wislowska M, Giudice RD, Lechinger J, Wielek T, Heib DPJ, Pitiot A, et al. Sci Rep. 2017; 7(1): 266. DOI: http://doi: 10.1038/s41598-017-00323-4

21. Thosar SS, Butler MP, Shea SA. Role of the circadian system in cardiovascular disease. J Clin Invest. 2018; 128(6): 2157-2167. DOI: https://doi: 10.1172/JCI80590

22. Boudreau P, Yeh W, Dumont GA, Boivin DB. Circadian Variation of Heart Rate Variability Across Sleep Stages. Sleep. 2013; 36(12): 1919-1928. DOI: https://doi: 10.5665/sleep.3230

23. Manoogian ENC, Panda S. Circadian rhythms, time-restricted feeding, and healthy aging. Ageing Res Rev. 2017; 39: 59-67. DOI: https://doi: 10.1016/j.arr.2016.12.006

24. Roy HA, Green AL. The Central Autonomic Network and Regulation of Bladder Function. Front Neurosci. 2019; 13: 535. DOI: https://doi: 10.3389/fnins.2019.00535

25. Wang H, Loh DH, Whittaker DS, Cutler T, Howland D, Colwell CS. Time-Restricted Feeding Improves Circadian Dysfunction as well as Motor Symptoms in the Q175 Mouse Model of Huntington's Disease.eNeuro. 2017; 5(1): ENEURO.0431-17. DOI: https://doi: 10.1523/ENEURO.0431-17.2017

26. French IT, Muthusamy KA. A Review of Sleep and Its Disorders in Patients with Parkinson's Disease in Relation to Various Brain Structures. Front Aging Neurosci. 2016; 8: 114. DOI: https://doi: 10.3389/fnagi.2016.00114

27. Folstein MF, Folstein SE, McHugh PR. "Mini-mental state". A practical method for grading the cognitive state of patients for the clinician.J Psychiatr Res. 1975; 12(3): 189-98. DOI: https://doi: 10.1016/0022-3956(75)90026-6

28. Kaufer DI, Cummings JL, Ketchel P, Smith V, MacMillan A, Shelley T, et al. Validation of the NPI-Q, a brief clinical form of the Neuropsychiatric Inventory. J Neuropsychiatry Clin Neurosci.2000; 12(2): 233-9. DOI: https://doi: 10.1176/jnp.12.2.233

29. Matsuda H. Voxel-based Morphometry of Brain MRI in Normal Aging and Alzheimer's Disease. Aging Dis. 2013; 4(1): 29-37.

30. Sone D, Imabayashi E, Maikusa N, Ogawa M, Sato N, Matsuda H, et al. Voxel-based Specific Regional Analysis System for Alzheimer's Disease (VSRAD) on 3-tesla Normal Database: Diagnostic Accuracy in Two Independent. Aging Dis. 2018; 9(4); 755-760. DOI: https://doi: 10.14336/AD.2017.0818

31. Okano Y, Tamura K, Kuji T, Masuda S, Tochikubo O, Umemura S. Effects of angiotensin II receptor blockers on relationships between 24-hour blood pressure, autonomic function, and health-related QOL. Clin Exp Hypertens. 2009; 31(3): 250-8. DOI: https://doi: 10.1080/10641960902822500

32. Nakamura M, Oda M, Akiba Y, Inoue J, Ito T, Tsuchiya M, et al. Autoradiographic demonstration of lansoprazole uptake sites in rat antrum and colon. J Clin Gastroenterol. 1995; 20 Suppl 2: S8-13. DOI: https://doi: 10.1097/00004836-199506002-00004

33. Schenck CH, Bundlie SR, Ettinger MG, Mahowald MW. Chronic behavioral disorders of human REM sleep: a new category of parasomnia.Sleep. 1986; 9(2): 293-308. DOI: https://doi: 10.1093/sleep/9.2.293

34. Höijer U, Hedner J, Ejnell H, Grunstein R, Odelberg E, Elam M. Nitrazepam in patients with sleep apnoea: a double-blind placebo-controlled study. Eur Respir J. 1994; 7(11): 2011-5.

35. Montagnese S, Zarantonell L, Formentin C, Zancato C, Bonetto MB, Biscontin A, et al. Sleep, Circa- 
dian Rhythmicity and Response to Chronotherapy in University Students: Tips from Chronobiology Practicals. J Circadian Rhythms. 2021; 19(1): 1. DOI: https:// doi.org/10.5334/jcr.202

36. Murofushi K. The mental world of the elderly with dementia of amnestic type (2). Japanese Journal of Geriatric Psychiatry. 1999; 10(10): 1187-1200.

37. Dubois B, Feldman HH, Jacova C, Dekosky ST, Barberger-Gateau P, Cummings J, et al. Research criteria for the diagnosis of Alzheimer's disease: revising the NINCDS-ADRDA criteria. Lancet Neurol.2007; 6(8): 734-46. DOI: https://doi: 10.1016/S1474-4422(07)70178-3

38. McKhann GM, Knopman DS, Chertkow H, Hyman BT, Jack Jr CR, Kawas CH, et al. The diagnosis of dementia due to Alzheimer's disease: recommendations from the National Institute on AgingAlzheimer's Association workgroups on diagnostic guidelines for Alzheimer's disease. Alzheimers Dement. 2011; 7(3): 263-9. DOI: https://doi: 10.1016/j.jalz.2011.03.005

39. McKeith IG, Galasko D, Kosaka K, Perry EK, Dickson DW, Hansen LA, et al. Consensus Guidelines fo the clinical and pathologic diagnosis of dementia with Lewy bodies (DLB): report of the consortium on DLB international workshop. Neurology. 1996; 47(5): 1113-24. DOI: https://doi: 10.1212/wnl.47.5.1113

40. McKeith IG, Boeve BF, Dickson DW, Halliday G, Taylor J, Weintraub D, et al. Diagnosis and management of dementia with Lewy bodies: Fourth consensus report of the DLB consortium. Neurology. 2017; 89(1): 88-100. DOI: https://doi: 10.1212/WNL.0000000000004058

41. Fiford CM, Ridgway GR, Cash DM, Modat M, Nicholas J, Manning EN, et al. Ian B. Patterns of progressive atrophy vary with age in Alzheimer's disease patients. Neurobiol Aging. 2018; 63: 22-32. DOI: https://doi: 10.1016/j.neurobiolaging.2017.11.002

42. Altman J, Das GD. Autoradiographic and histological evidence of postnatal hippocampal neurogenesis in rats. J Comp Neurol.1965. 124(3): 319-335. DOI: https://doi: 10.1002/cne.901240303

43. Sreenivasmurthy SG, Liu JY, Song JX, Yang CB, Malampati S, Wang ZY, et. al. Neurogenic Traditional Chinese Medicine as a Promising Strategy for the Treatment of Alzheimer's Disease. Int J Mol Sci. 2017. 28;18(2):272. DOI: https://doi: 10.3390/ijms18020272

44. Ju YES, Ooms SJ, Sutphen C, Macauley SL, Zangrilli MA, Jerome G, et. al. Slow wave sleep disruption increases cerebrospinal fluid amyloid- $\beta$ levels. Brain. 2017. 1;140(8):2104-2111. DOI: https:// doi: 10.1093/brain/awx148

45. Murphy MP, LeVine 3rd H. Alzheimer's disease and the amyloid-beta peptide. J Alzheimers Dis. 2010. 19(1):311-23. DOI: https:// doi: 10.3233/JAD-2010-1221

46. Valdes-Tovar M, Estrada-Reyes R, Solis-Chagoyan H, Argueta J, Dorantes-Barron AM, Quero-Chavez D, et. al. Circadian modulation of neuroplasticity by melatonin: a target in the treatment of depression.Br J Pharmacol. 2018. 175(16):3200-3208. DOI: https:// doi: 10.1111/bph.14197

47. Fernandes C, Rocha NBF, Rocha S, Herrera-Solis A, Salas-Pacheco J, Garcia-Garcia F, et. al. Detrimental role of prolonged sleep deprivation on adult neurogenesis. Front Cell Neurosci. 2015. 14;9:140. DOI: https:// doi: 10.3389/fncel.2015.00140

48. Sack M, Lenz JN, Jakovcevski M, Biedermann SV, Falfan-Melgoza C Deussing J, et. al. Early effects of a high-caloric diet and physical exercise on brain volumetry and behavior: a combined MRI and histology study in mice. Brain Imaging Behav. 2017. DOI: https:// doi: 10.1007/s11682-016-9638-y

49. Chen ISH. The circadian rhythm of Yin and Yang Syndrome on hypertension. Chinese Journal of Integrated Traditional and Western Medicine. 1998. 4(2):95-99. DOI: https://doi.org/10.1007/BF02934150

50. Zhang HJ, Wang ZX. Yin-yang and Zheng: Exported from Chinese medicine.Chinese Journal of Integrated Traditional and Western Medicine.2014. 20(4):250-255. DOI: https://doi.org/10.1007/s11655014-1777-z

51. Fisk AS, Tam SKE, Brown LA, Vyazovskiy VV, Bannerman DM, Peirson SN. Light and Cognition: Roles for Circadian Rhythms, Sleep, and Arousal.Front Neurol. 2018. 9:56. DOI: https:// doi: 10.3389/fneur.2018.00056

52. Potter GDM, Skene DJ, Arendt J, Cade JE, Grant PJ, Hardie LJ. Circadian Rhythm and Sleep Disruption: Causes, Metabolic Consequences, and Countermeasures. Endocr Rev. 2016. 37(6): 584608. DOI: https:// doi: 10.1210/er.2016-1083 
53. Terasawa K. On the Term Mind-Body Unity, an Etymological Review.Kampo Med. 2018. 69(2):199201. DOI: https://doi.org/10.3937/kampomed.69.199

54. Terasawa K. On the Mind-Body Unity in the Oketsu Syndrome. Kampo Med. 2018. 69(1):67-71. DOI: https://doi.org/10.3937/kampomed.69.67

Legend of Figure 1

We define the inspection at the time of the intervention with the chronobiological therapy as the first one and define the inspection after the intervention as the second one. The 1st scores of VSRAD were 1.48 to 5.7 and the average was 3.085. The 2 nd $\mathrm{Z}$ scores were 0.93 to 5.58 and the average was 2.727 .

Legend of Figure 2

The 1st MMSE scores were 11 to 25 and the average was 16.2. The 2nd MMSE scores after the intervention were 10 to 29 and the average was 18.5 .

Legend of Figure 3

The 1st severities of Neuropsychiatric Inventory-Questionnaire (NPI-Q) in Case 4 and 5 were 20 and 21, and the average was 20.5. The 2 nd severities of NPI-Q were 9 and 2 , the average was 5.5 .

Legend of Figure 4

The 1st VSRAD Z-scores were 1.48 to 5.7 and the 1st MMSE scores were 11 to 25 points. This Pearson correlation coefficient was -0.353 .

Legend of Figure 5

The 2nd Z-scores were 0.93 to 5.58 and the 2nd MMSE scores were from 10 to 29 points. This Pearson correlation coefficient was -0.549 .

Legend of Figure 6

The 1 st $\mathrm{Z}$ scores were 1.48 to 5.7 and the $2 \mathrm{nd} \mathrm{Z}$ scores were 0.93 to 5.58. This Pearson correlation coefficient was 0.965 .

Legend of Figure 7

The 1st MMSE scores were 11 to 25 and the 2nd MMSE score were 10 to 29. This Pearson correlation coefficient of was 0.843 .

Legend of Figure 8

We achieved the recovered 0.03 to 1.28 points of VSRAD Z-score. They were improvement rates of Z-scores (Imp Z). The Pearson correlation coefficient between these recovered points and the 1st MMSE scores was 0.872 .

Legend of Figure 9

The Pearson correlation coefficient between these Imp Z and the 2nd MMSE scores was 0.740.

Legend of Table 1

The table shows milligram quantity of the medicines. Lansoprazole, furosemide, and spironolactone create the activities of the autonomic nervous system in the morning. Conversely, clonazepam and nitrazepam create an end of the activities of autonomic nervous system at night.

Legend of Table 2

The table shows gram quantity of the Japanese Kampo Medicines (JKMs). Ninjin-Yoei-To has an effect on decreased physical strength, fatigue, inappetence, night sweats, coldness of hands and feet, and anemia. Toki-Syakuyaku-San has an effect on anemia, fatigue, and edema. Hochu-Ekki-To treats decreased physical 
strength, inappetence, and gastroptosis. Bohu-Tsusho-San treats palpitation, stiff shoulder, obesity, and constipation. Yokkan-San and Yokkan-San-Ka-Chinpi-Hange act on irritation and insomnia. Keishi-KaShakuyaku-To has an effect on stomachache. Oren-Gedoku-To has an effect on hypertension, insomnia, vertigo, and dermatitis. Choto-San has an effect on headache and hypertension.

Legend of Table 3

The table shows gram quantity of the ingredients of Japanese Kampo Medicines (JKMs). Toki, Japanese Angelica Root, creates the start of the activity of the autonomic nervous system. Chotoko, Uncaria Hook, creates the closure of the activity of the autonomic nervous system.

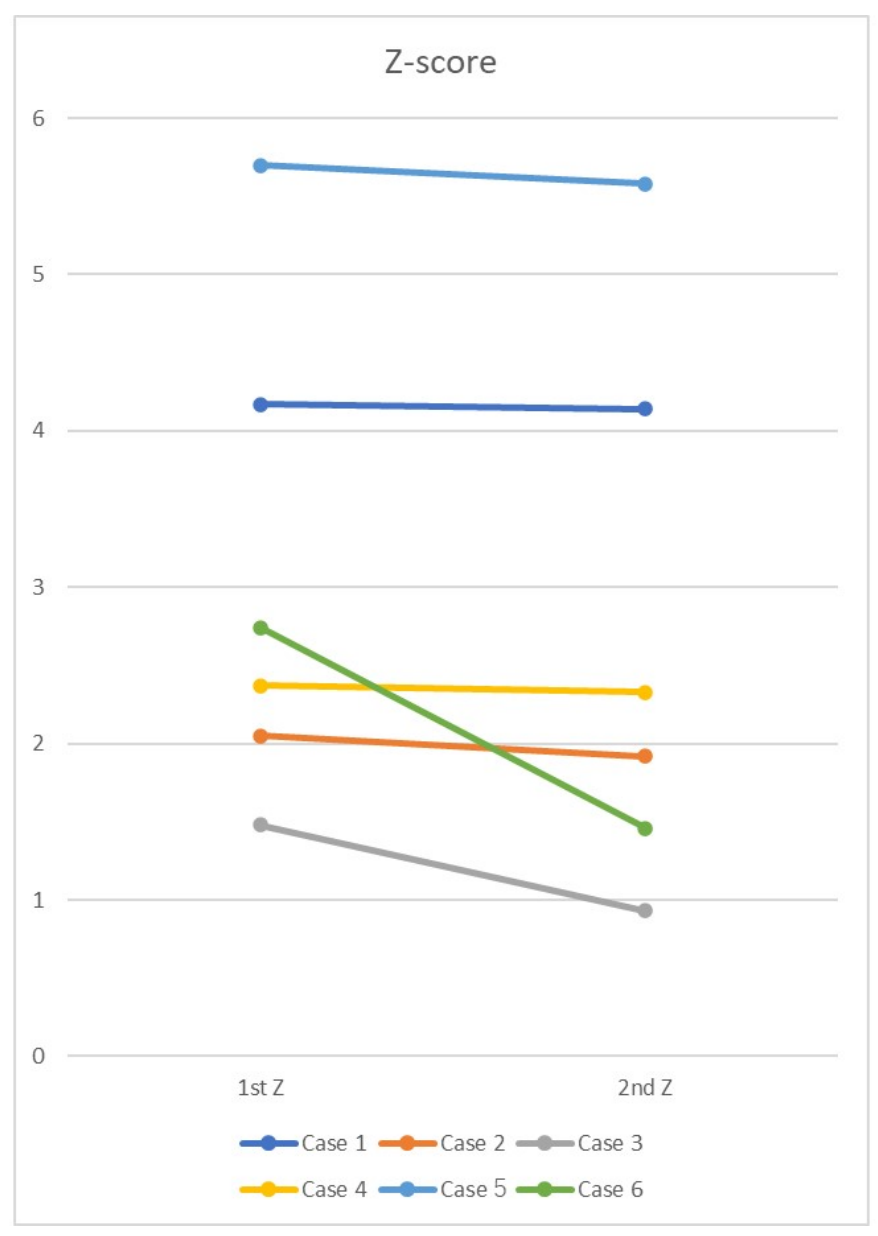




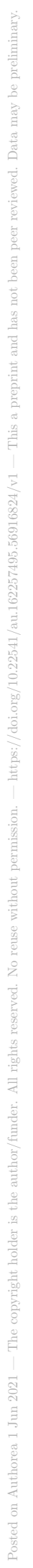

MMSE score

35

30

25

20

15

5

0

1st MMSE

2nd MMSE

$\longrightarrow$ Case $1 \multimap$ Case $2 \longrightarrow$ Case 3

$\longrightarrow$ Case $4 \longrightarrow$ Case $5 \multimap$ Case 6

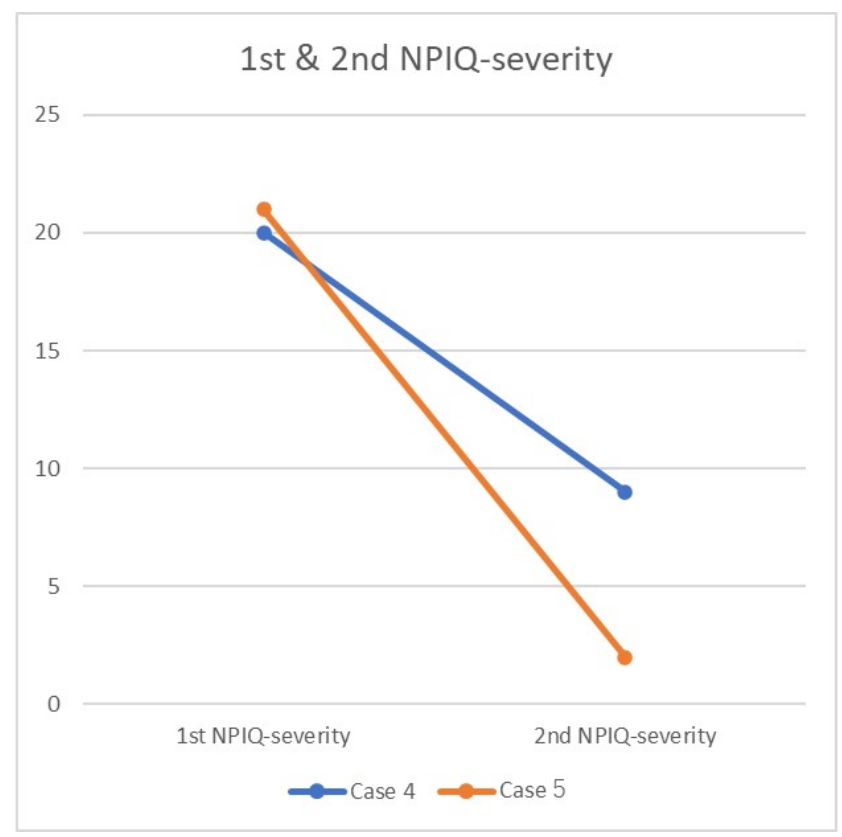

14 

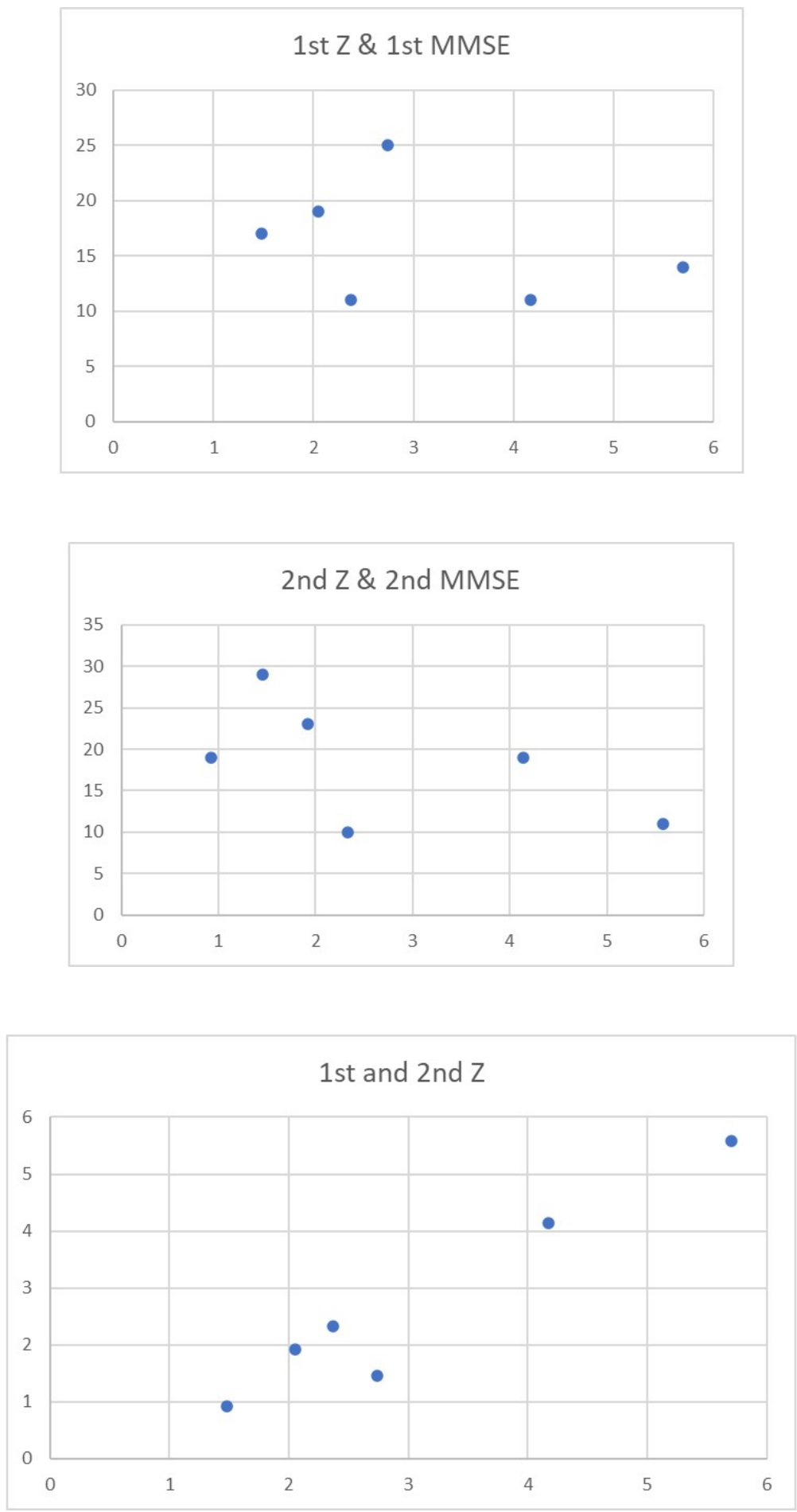

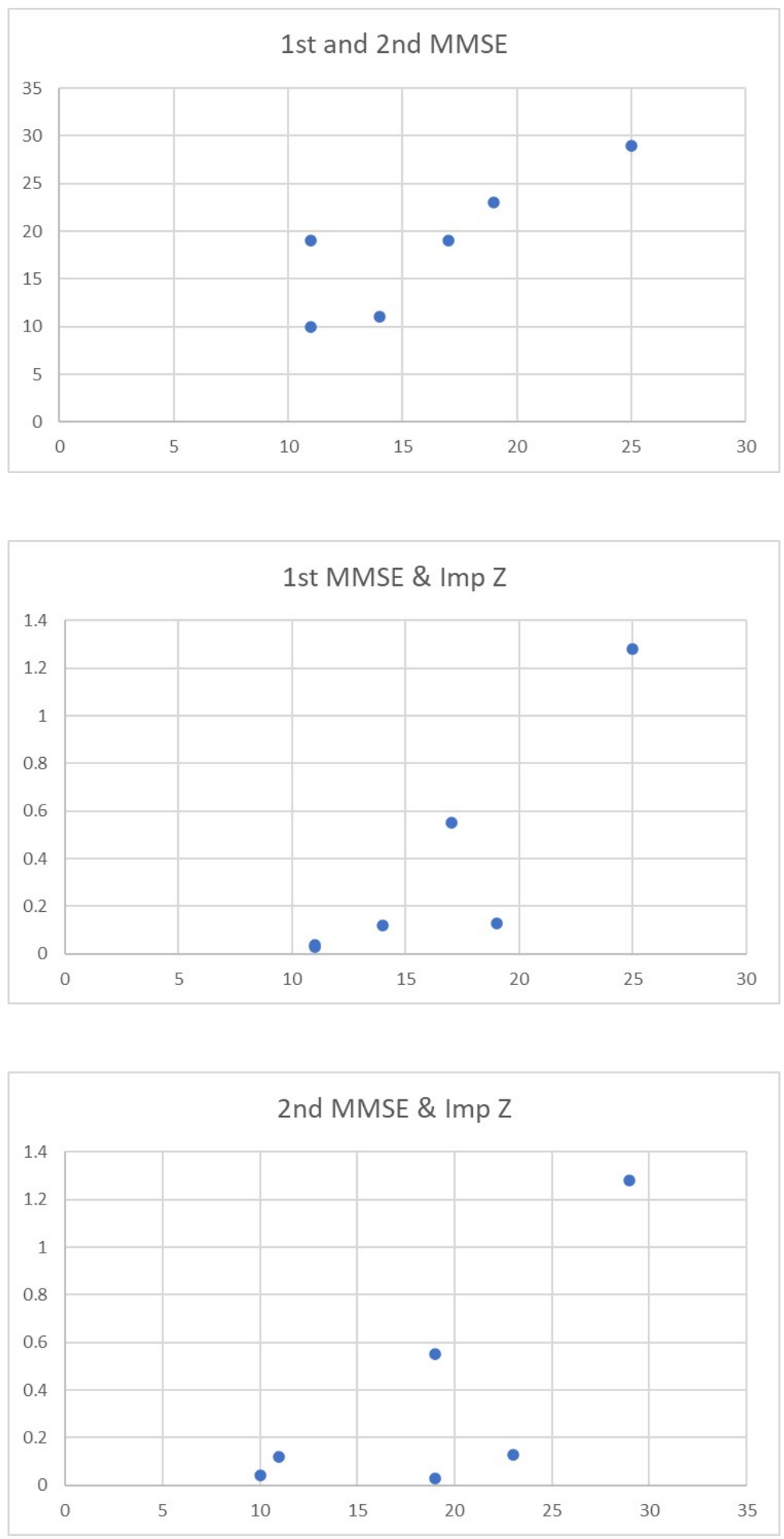


\begin{tabular}{|l|r|r|r|r|r|r|}
\hline Case & 1 & 2 & 3 & 4 & 5 & 6 \\
\hline \hline lansoprazole & 15 & & 15 & & 15 & 15 \\
\hline furosemide & & & & 20 & & 10 \\
\hline spironolactone & & & & 25 & & \\
\hline valsartan & & & & 80 & & \\
\hline rivastigmine & & & & & & 4.5 \\
\hline clonazepam & 0.25 & 0.25 & 0.25 & 0.25 & 0.125 & 0.5 \\
\hline nitrazepam & 2.5 & 2.5 & 2.5 & & & 2.5 \\
\hline
\end{tabular}

\begin{tabular}{|l|r|r|r|r|r|r|}
\hline Case & 1 & 2 & 3 & 4 & 5 & 6 \\
\hline \hline Ninjin-Yoei-To & 6 & & & & & \\
\hline Toki-Syakuyaku-San & & 1.25 & & & & \\
\hline Hochu-Ekki-To & & & & 2.5 & & \\
\hline Bohu-Tsusho-San & & & 7.5 & & & \\
\hline Yokkan-San & & 5 & & & & 7.5 \\
\hline Yokkan-San-Ka-Chinpi-Hange & & & 2.5 & 7.5 & 2.5 & \\
\hline Keishi-Ka-Shakuyaku-To & & & & & 5 & \\
\hline Oren-Gedoku-To & 7.5 & & & 5 & & \\
\hline Choto-San & 7.5 & & & 5 & & \\
\hline
\end{tabular}

\begin{tabular}{|l|r|r|r|r|r|r|}
\hline Case & 1 & 2 & 3 & 4 & 5 & 6 \\
\hline \hline Toki & 2.67 & 2.5 & 2.2 & 4 & 1 & 3 \\
\hline Chotoko & 3 & 2 & 1 & 3 & 1 & 3 \\
\hline
\end{tabular}

